\title{
LEONARDO DA VINCI AS PHYSIOLOGIST
}

\author{
By K. D. KeELE, M.D.; F.R.C.P. \\ (Based on a Paper delivered to the Osler Club. 18th April 1952)
}

It is of course in the art (or as Leonardo would have called it, the 'science') of representing the parts of the human body that Leonardo stands preeminent, but beyond this task of anatomical illustration Leonardo always searched into the problems of function which lay inherent in the accurate representation of each 'instrument of the body.'

At the outset he realized that no intelligent discussion of the function of an organ can be undertaken without a clear knowledge of its structure. For many years Leonardo took delight in representing human organs with all his realistic artistry; later on we find his figures becoming less artistic as they become instruments designed to illustrate conceptions of function rather than naturalistic representations, a change that reflects his increasing interest in physiology.

In a passage that reads as if it were written as a preface, written with a view to publication, Leonardo writes: "Therefore there shall be revealed to you in 15 complete figures the cosmography of the minor mondo (the microcosm or lesser world) in the same order as was used by Ptolemy before me in his cosmography. And therefore I shall divide the members as he divided the whole into provinces, and then I shall define the functions of the parts from all aspects, placing before your eyes the knowledge of the whole figure and healthy capacity of man in so far as it has local movement by means of its parts.' It will be noted here that 'local movement' was what interested Leonardo. 'Movement is the cause of all life,' he says.

Physiology for Leonardo, then, is mainly the study of all movement in the body, which he appreciates is governed by the senses and the soul.

Having represented to his own satisfaction the 'instruments' of the body as he repeatedly calls human organs, he proceeds to analyze their action.

In this analysis he utilizes three lines of attack:

I. His own mechanical principles.
2. The Galenic principles of physiology.

3. The analogy between the macrocosm and the microcosm as mentioned in the above quotation.

All his physiological views will be found to contain a blend of these three components.

The macrocosm-microcosm analogy is repeatedly cited in Leonardo's notes. In one example he gives his reasons for accepting its importance - "Man has been called by the ancients a lesser world, and indeed the term is rightly applied; seeing that man is compounded of earth, water, air and fire, this body of the earth is the same. And as man has within himself bones as ao stay and framework for the flesh, so the world has the rocks which are the supports of the earth, and as man has within him a pool of blood wherein the lungs as he breathes expand and contract, so the body of the earth has its ocean which also rises and falls every six hours with the breathing of the world. As from the said pool of blood proceed the veins which spread their branches through the human body, in just the same way the ocean fills the body of the earth with an infinite number of veins of water. And the vital heat of the world is fire which is spread throughout the earth-and is breathed out in baths and volcanoes, such as Mount Etna in Sicily.

Leonardo even pushes the analogy to the extent of discovering world growth through the element of air, and world death ' in the element of fire. Then the surface of the earth will remain burnt to a cinder, and this will be the end of all terrestrial nature.' Is not this catastrophic world death the subject of the so-called 'deluge drawings?' This macrocosm-microcosm analogy must have played an important part in leading Leonardo to apply the results of his studies in mathematics, physics, hydrostatics, geology and geography to the physiology of the human body.

The influence of the great Galen was transmitted to Leonardo through the distorting media of Avicenna and Mondino, direct access to Galen's work must have been slight since Leonardo knew 
no Greek; it was probably limited to the short period about I5 IO when he worked with Marc Antonio della Torre. Galen's physiology Leonardo treated with stern criticism, divesting it almost entirely of its many ' spirits,' ' faculties,' ' coctions' and the variety of ' humours,' which terms hardly ever appear in his notes. But he retained to the end some fundamentals such as the nature of the movement of the blood in ebb and flow.

These two influences, on the whole, impeded Leonardo's progress in physiology. Almost all his advances may be attributed to his vigorous and original application of his third principle, that of mechanics, to the instruments of the body which he discovered for himself-discovered in the sense that though in some cases their existence may have been previously known his was the first eye to perceive many organs with that accuracy necessary to the fruitful application of mechanical laws.

The laws applied by Leonardo seem to have arisen from his studies on movement and force. The laws of movement contained laws of life. ' Force, with material movement, and weight, with percussion, are the four accidental powers in which all the works of mortals have their being and their end.'

In the plan for his book on anatomy and physiology he says, "Arrange it so that the book of the elements of mechanics with examples shall precede the demonstration of movement and force in man and the other animals, and by means of these you will be able to prove all your propositions.'

And alongside the scheme for the anatomy he lays down his physiological principles under the significant heading 'Machines.' 'Why nature cannot give the power of movement to animals without mechanical instruments, as is shown by me in this book on the works of movement which nature has created in animals. And for this reason I have drawn up the rules of the four powers of nature without which nothing through her can give local movement to these animals. We shall first describe this local movement and how it produces and is produced by each of the other three powers ...'

Each of these 'four powers' is defined and discussed at great length by Leonardo, but to follow him would lead us too far from our present subject of physiology. Throughout it all the emphasis lies strongly on the closeness of movement, heat and life. 'Movement is the cause of all life. Movement is created by heat and cold.' The movement of the elements arises from the sun ' and the heat of the sun gives life to all things and forms the vital spirits. Where there is life there is heat, and where there is vital heat there is movement of the watery humours.'
These are principles which he considered to underly both the movement of the blood in man as well as the rising of mists and the falling of raig in a perpetual circulation. And the function of theheart he saw as a source of friction, its movement providing the main source of body heat, as fire within does for the world. To summarize Leonardo's physiology is, in fact, an analysis of all the movements of the body

With these views, combined with his artistie interest in muscle and bone and his intense attach on the problem of the flight of man, it is no surprising that Leonardo's greatest physiologicat contributions are in the field of muscle action. $\vec{\omega}$

The analysis of the posture of standing is carrie right down to the curvatures of the spine with success which even Vesalius failed to achieve. The movement of the bones of the forearm ifp pronation and supination was a revelation oce mechanical action which fascinated him so muct that there are at least ten detailed studies of it. from all aspects and with the elbow extended and flexed; he even noted that flexion of the elbow restricts the rotation of the head of the radius.

By his emphasis on the movement of bones he drawings become illustrations of actions, of physiology - so that as Holl has quaintly saif, his skeletons 'live.' These skeletal forms ofhe clothed with muscles always with a view to undertw standing the 'local movement' of both the muscles and bones of the part. Movement if man is voluntary, and commences therefore in the soul which, says Leonardo, ' resides in the seap of judgment where all the senses come togethe which is called the senso commune,' and he pro ceeds to describe how sight, hearing, smell and touch are all brought by their nerves to this region (Fig. I).

'These nerves,' he says, ' proceed to spread oute with infinite ramifications into the skin which en closes the body's members and bowels. The peto forated nerves carry stimulus and sensation to. the subject limbs and muscles ... they dictate th these their movements and these obey, so con tracting for the reason that the swelling reduces their length ... . The tendons with their muscles serve the nerves even as soldiers serve the leaders, and the nerves serve the senso commun as the leaders their captain, and the senso comp mune serves the soul as the captain serves his lordo And the senso commune is the seat of the sout memory is its monitor and the "imprensiva" is its reference standard.'

Involuntary movement is also recognize ${ }^{\circ}$ ' This appears clearly, for you will see how paralytics or those who are shivering move thein trembling limbs ... without permission of the soul; which soul with all its powers cannot pres 


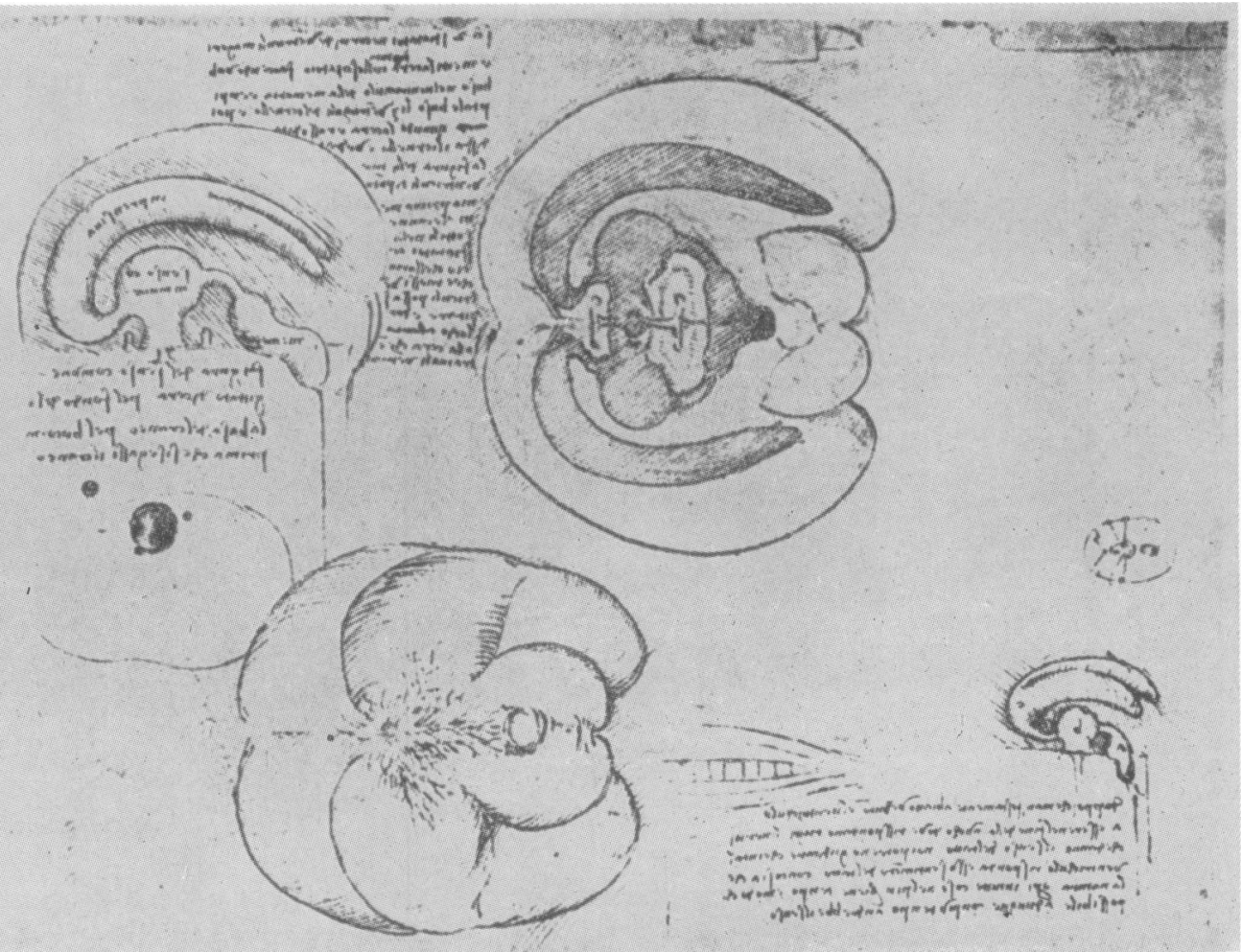

Fig. I.-Leonardo's demonstration of the ventricles of the brain by injection of wax. The text on this page describes the method of performing this. The site of the 'senso commune' is in the third ventricle. The 'imprensiva' is located in the lateral ventricles.

vent these limbs from trembling. The same happens in the case of epilepsy, or with severed limbs such as the tails of lizards.'

He judged the part played in movement by the spinal cord from his experiment of pithing a frog-the first experiment on the central nervous system since Galen. 'The frog instantly dies when the spinal cord is pierced, and previous to this it lived without head, heart or any bowels or skin, and here, therefore, it would seem lies the foundation of movement and life.'

The force exerted by muscle action was of the utmost interest to him and he analyses it at length in his typically painstaking manner. 'If any muscle be drawn out lengthwise a slight force will break its fleshy tissue, and if all the nerves be drawn out likewise slight power tears them from the muscles ... and one sees the same process enacted with the fibrous coverings of the veins and arteries which are mingled with these muscles. What is therefore the cause of so great a force of arms and legs which is seen in the actions of any animal? One cannot say other than that it is the skin (or fascia) which clothes them, and that when the nerves thicken the muscles these muscles contract and draw after them the tendons ... . and in this process of thickening they fill out the skin (fascia) and make it hard, and it cannot be lengthened out unless the muscles become thinner, and not becoming thinner they are a cause of resistance and of making strong the aforementioned fascia in which the enlarged muscles perform the function of a wedge.'

The action of each muscle he demonstrated by pulling it ' in such a way as to see the muscle move and its origin from the ligaments of the bones.' As a result of this procedure he conceived the idea of representing them by threads (Fig. 2).

'You will make nothing but confusion in your demonstration of the muscles and their positions, origins and insertions, unless you first make a demonstration of the slender muscles by means of threads; and in this way you will be able to represent them one above another as nature has placed them, and so you will be able to name them 


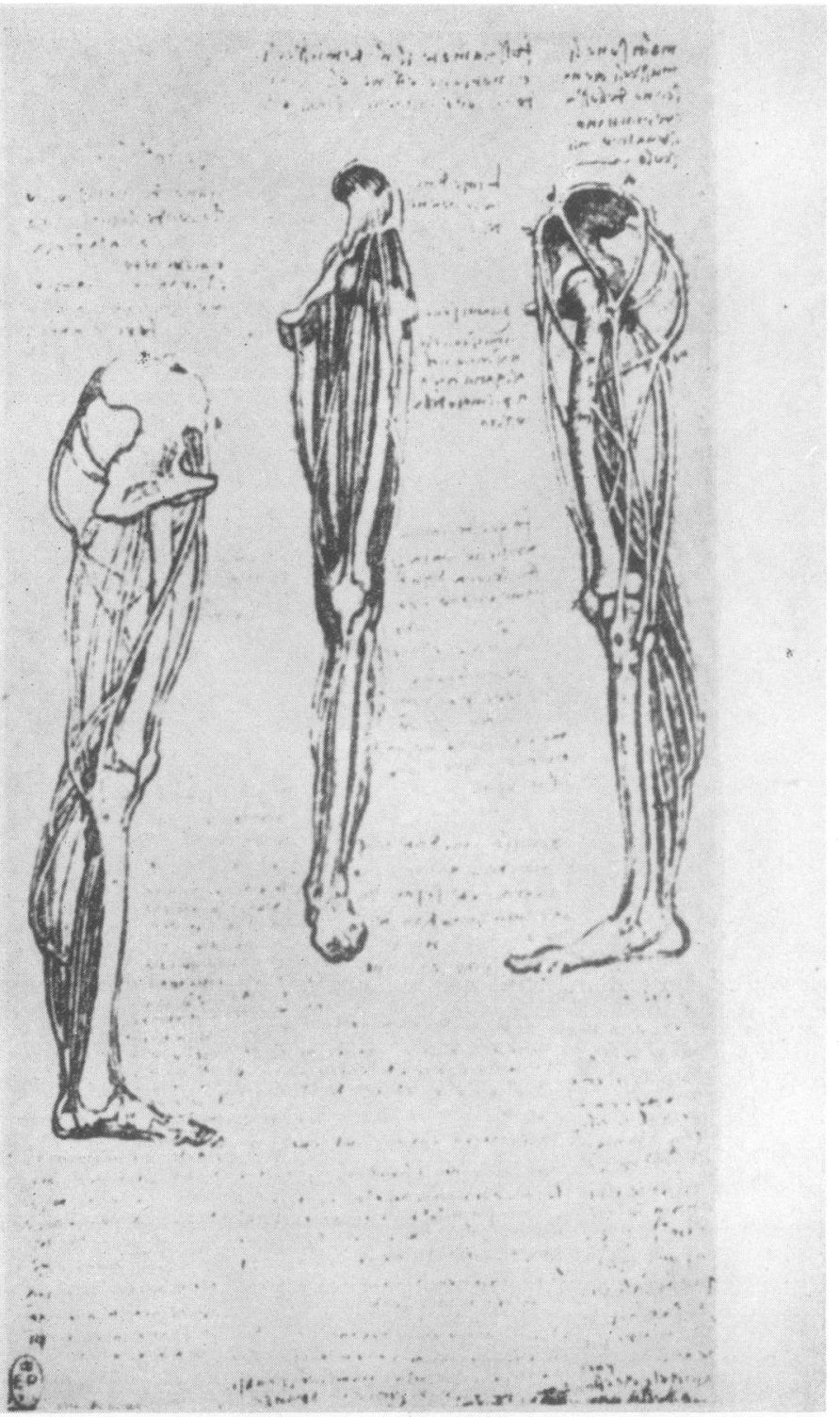

according to the member that they serve ... Remember to make the threads that denote the muscles in the same positions as the central line of each muscle. Every muscle uses its power along the line of its length.' So that these threads represent for him lines of force.

In relation to the action of sartorius and tensor fasciae lata he points out that with their action of flexion of the hip there is relaxation of the antagonists gluteus medius and part of gluteus maximus-noting that 'this rule is to be dese cribed in the action of all the muscles.' He thus states the rule that when a muscle contracts it antagonist relaxes, a rule that was established an $\$$ elaborated by the work on reciprocal innervation

carried out by Sir Charles Sherrington.
But of all the muscles in the body the heart re $\frac{\bar{\phi}}{\Phi}$ ceived more attention from Leonardo than an 
other, and in this matter he started off with the disadvantage that his authorities considered the heart not to be a muscle at all, a statement made repeatedly by Galen who endowed it with a 'pulsative faculty.'

It was a great step therefore when Leonardo explained this 'faculty' in the words 'the heart in itself is not the beginning of life but it is a vessel made of thick muscle vivified and nourished by the artery and vein as are the other muscles.'

$\mathrm{He}$ considered that the heart muscle was arranged in longitudinal and transverse fibresthe former on contraction producing shortening and widening of the ventricular cavities, an action which sucked in blood in a manner similar to the inspiration of air into the chest. Contraction of the transverse fibres elongated and narrowed the chambers so expelling their contained blood.

In one experiment, that on the pigs in Tuscany, he comes to a contrary conclusion, i.e. that the heart shortens in systole but does not appear to follow up the point.

A great deal of attention was given to the question of the number of chambers in the heart. Galen considered there were two main ventricles with a small but mysteriously located third one between them. This error Avicenna exaggerated. Both these authorities, with Mondino, considered the auricles as diverticula of the vena cava and pulmonary veins outside the heart useful for storing excess blood or air-the atria themselves being merely the dilated mouths of these veins. Leonardo accepted this at first as shown in many of his drawings but later changed to the view that the heart consists of four main chambers, not two (Fig. 3).

He devotes more attention to establishing this point than to any other single topic in his anatomical manuscripts, so that it is evident that he attached great importance to the discovery.

From the physiological point of view the significance of the four-chambered heart was that it provided a mechanism for the supply of heat, which he considered the essential function of the heart. Galen had called such heat 'innate,' leaving its source a mystery; Leonardo thought to supply the answer by the friction of blood tossed from ' upper ventricles,' as he called the atria, to lower. "The auricles of the heart were made in the shape of dilatable purses only to receive the percussion of the movement which the blood makes driven violently out of the ventricles, both right and left, when they contract themselves .... and they (the auricles) contract themselves giving back the blood to these internal ventricles.'

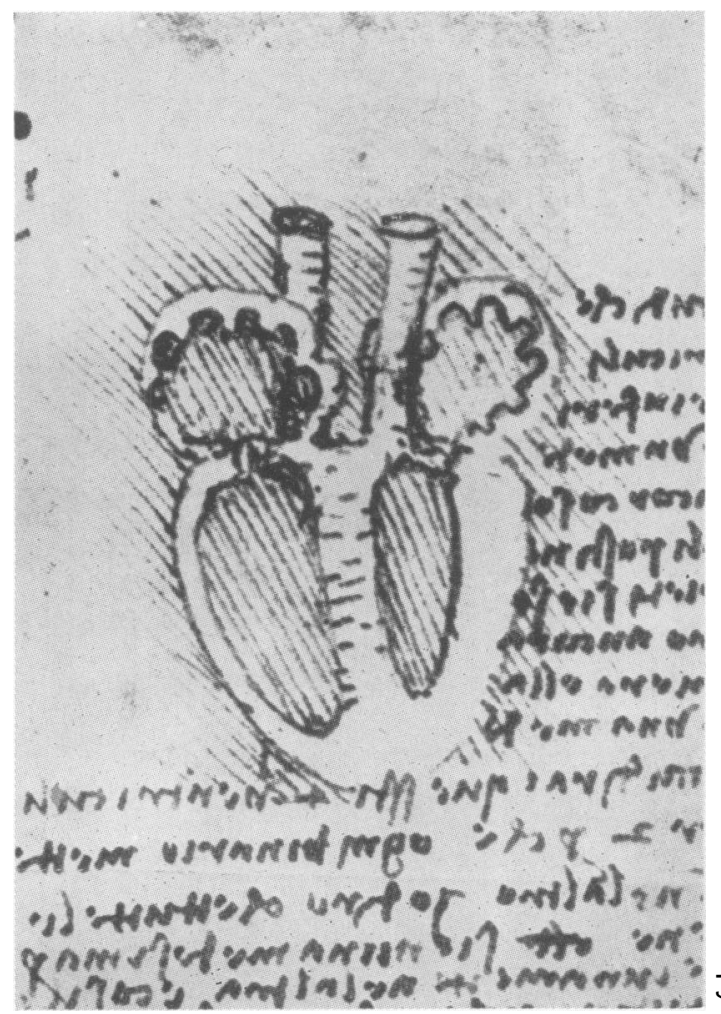

FIG. 3.-Leonardo's illustration of the heart as a fourchambered organ with upper ventricles or atria of a size equivalent to the lower. The hypothetical septal pores are also represented.

' Observe when butter is being made whether the milk as it revolves is heated, and by such means you will be able to prove the efficacy of the ventricles of the heart which receive and expel the blood from their cavities and other passages made only in order to heat and refine the blood.'

'Flux and reflux of blood,' that is the phrase which time and again he uses to describe the action of the upper and lower ventricles, 'and the revolution which the blood makes within itself whirling round in diverse eddies, and the friction which it makes against the walls and the percussion in these depressions are the cause of the heating of the blood.' And the whole theory is elaborated in several passages which purport to answer the objections raised by an ' adversary,' which term he presumably applies to one supporting the orthodox Galenic view.

It will be noted that in the passages quoted there is no mention of air in either ventricle. Though this idea had come down from Galen, Leonardo discarded it as a result of his failure, when inflating the lungs of an animal with bellows, to make any 

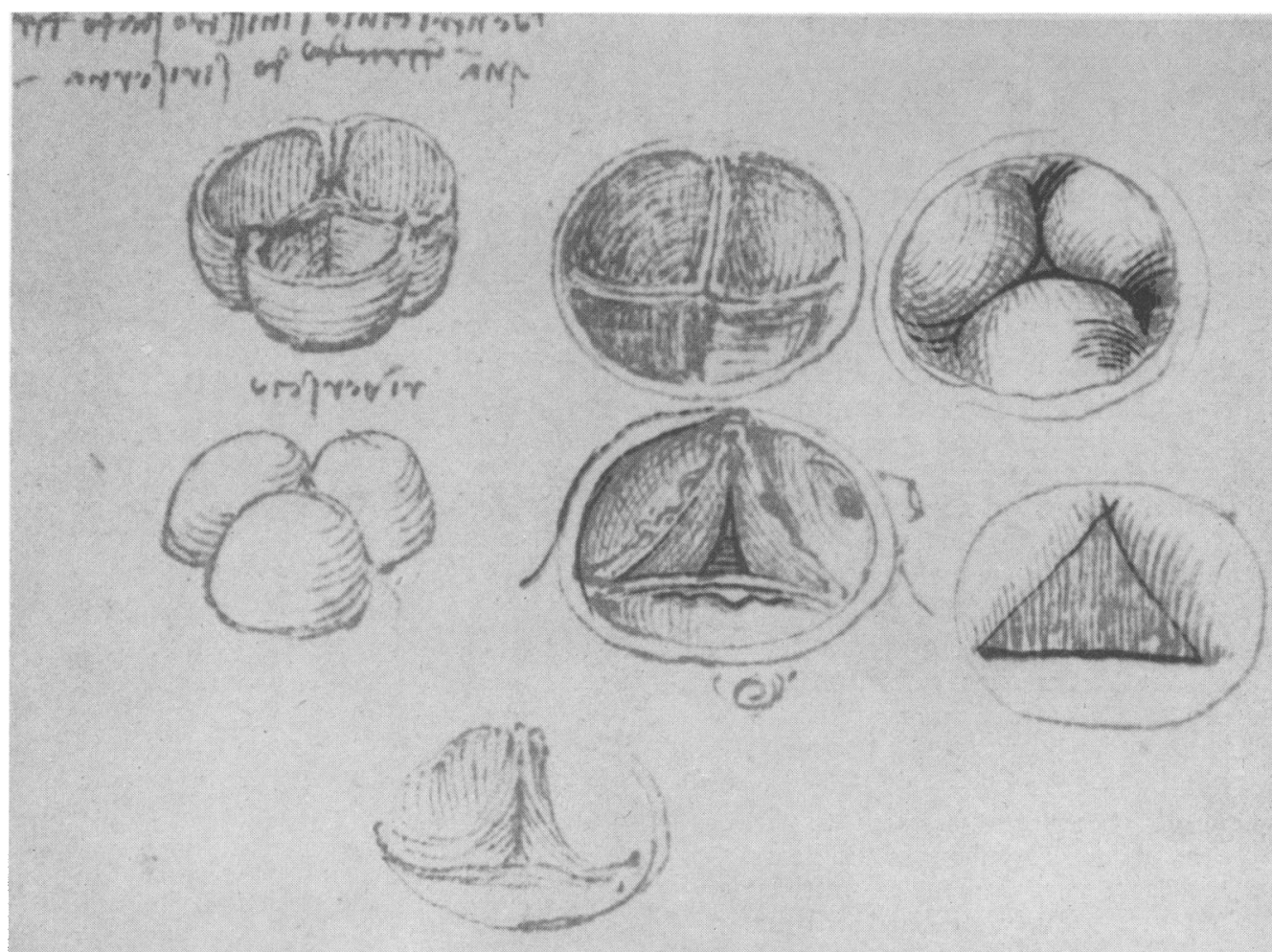

FIG. 4.-Representation of the cusps of the aortic valve open and closed from above and
edge of the valve cusps in the central figure, with the origin of the coronary arteries.

air get into the heart. It is perhaps of interest that Harvey found it necessary to repeat the same experiment over 100 years later.

All the valves of the heart received attention from Leonardo, but most of all the aortic (Fig. 4). Of this valve he made a glass cast, and it would seem he observed the movements of the cusps as fluid passed through. His representations of the valve, open and closed, are beautifully accurate and informative. He noted the triangular shape left by the valves when opened, and from this observed or deduced (one will not be sure which word is true until the experiment is repeated) that three main eddies of blood are formed each of which, curling back, form the hollowed out sinuses named after Valsalva, and close the aortic valve cusps from below rather than from above.

In a drawing of the aortic valve from above he shows its wavy edge in a way not demonstrated until this year, 1952, by cinematography and reported in the British Heart Fournal. This, surely, was observation. But in this description. of eddies with their counter eddies he saw forces which ' consume their impetus towards the centre of the circumvolution, by which process the velocity is retarded until the impetus consumes? itself.' Here he conceives of the movement of blood stopping at the periphery of the artery-an evento clearly incompatible with circulation as Harvey demonstrated it. But to Leonardo it was the heat of the heart that supplied the chief motive forces of the blood and not so much its contraction? The blood went out of the heart in a mannero reminiscent of smoke going up a chimney-by convection current due to its heat, and returnedo again when cool. Just as water is raised by the sun, or spouted out in hot springs, and falls back to the earth when cool and condensed under the influence of gravity, so the blood in the bodys circulated according to Leonardo.

Another form of circulation of blood was postulated by Leonardo. According to Galeno blood was formed from food in the liver whenceo it went by veins to nourish the tissues and organs $\frac{.}{\mathrm{x}}$ the remnant or superfluous blood was not? accounted for by Galen. Leonardo steps in hereo and suggests that this superfluous or used blood is ${ }_{\vec{P}}$ finally conveyed by the mesenteric arteries to the 


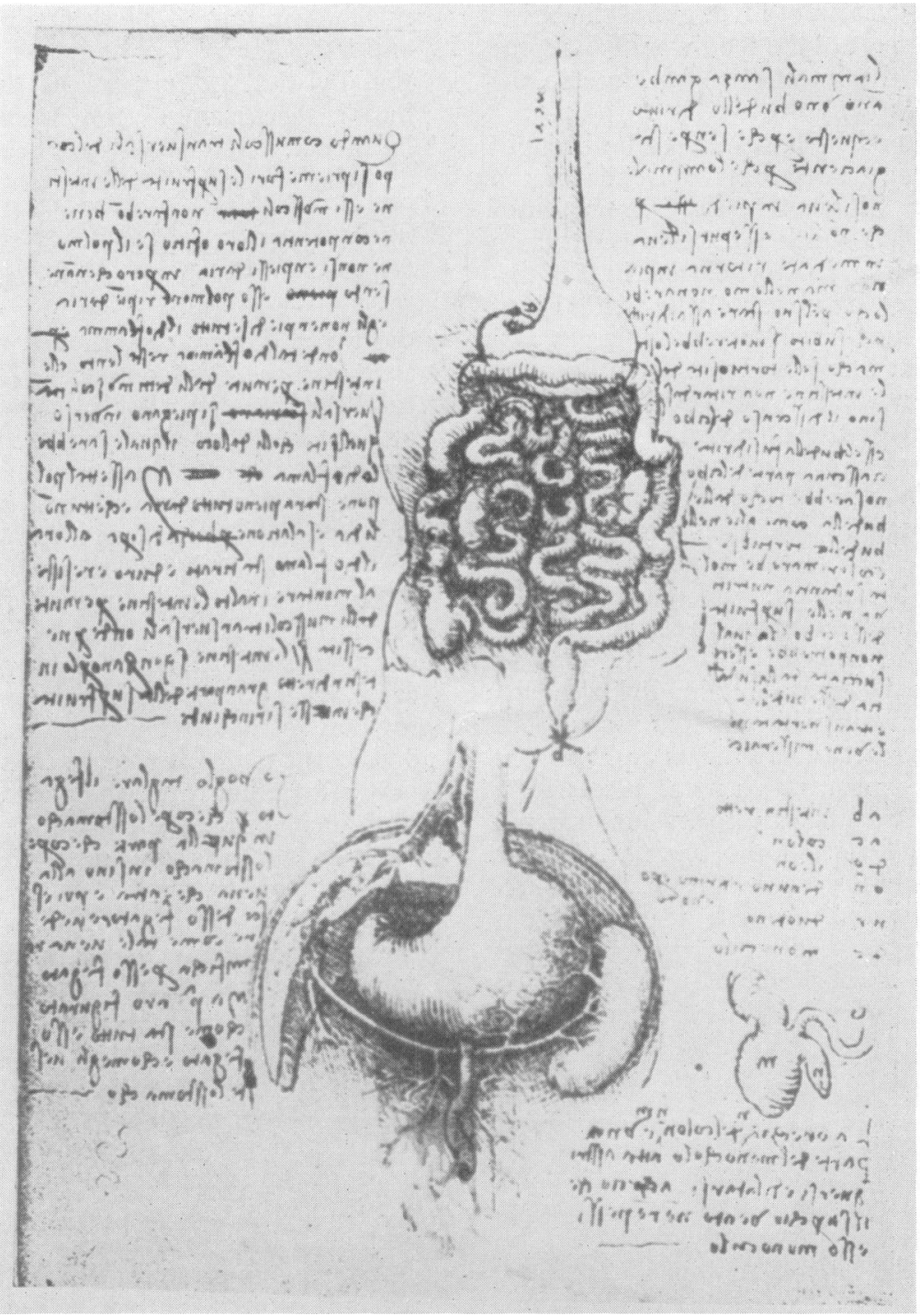

FIG. 5.-Leonardo's drawing of the stomach and intestines with detailed representation of the caecum and appendix in the right lower corner.

intestine where it makes the faeces. Thus there would be a circulation of blood materials to and from the intestine.

Two forms of circulation of blood he conceived of, and both were wrong. If he had lived longer would he have thought of the right one?

Leonardo's success in attacking the mechanical problems of physiology is in contrast with his failure to contribute to problems which are not amenable to such treatment.

This is exemplified in his physiology of digestion. Though, as usual, he succeeds in illustrating the stomach and intestines in a manner incomparably better than any before him (Fig. 5), he proceeds to try and solve the problems of digestion by applying his 'four powers' with results that are not without a touch of humour to us in their simplicity.

For example, 'Animals without legs have a straight bowel and that is why they always remain lying down .... but in the case of man this would not take place by reason of him holding himself upright, because the stomach would suddenly empty itself if the coiled nature of the intestines 
did not check the descent of food, and if the bowel were straight each part of the food would not come into contact with the intestines as it does in the coiled bowels.'

Absorption of food he considers to be brought about by mechanical suction at the ends of the mesenteric veins. 'I say that the extremities of the mesenteric veins which attract to themselves the substance of the food enclosed in the intestines are enlarged by means of the natural heat of man, because heat separates and enlarges and cold constricts, but this would not be sufficient if to this heat were not added the foetid gas formed by the corruption of the blood returned by the arteries to the intestines which enlarges the holes through which the mesenteric veins suck up the food.' This ingenious mechanical physiology is a logical application of his 'four powers' to the problem of food absorption. Its deficiencies lie in Leonardo's resistance against recognizing the phenomena of a chemistry of life. In this case he would have done better to retain Galen's conception of ' coction' in which this is recognized. The mechanical aspects of alimentary physiology are, as we would expect, much more successfully dealt with. Leonardo takes priority for example in correlating the forms of the teeth with their different functions of tearing, cutting and grinding. $\mathrm{He}$ makes detailed and accurate analysis of the forces created by the diaphragm and abdominal muscles in the act of defaecation, and if he attributes to the appendix the function of preventing rupture of the caecum by taking up superfluous wind, what better suggestion has been made since?

I have mentioned that Leonardo was critical of the possibility of chemical changes in the body. This attitude was largely prompted by his distrust of alchemists and all their works. 'Alchemy,' he says, 'works by the simple products of nature, but its function cannot be exercised by nature herself because there are in her no organic instruments with which she might be able to do the work which man performs with his hands, by the use of which he has made glass, etc.'

Presumably the changes the alchemist wrought with his furnaces and strong acids and alkalis seemed too coarse to apply to changes in living bodies. The ' organic instruments' whose absence Leonardo deplores were only to appear when the enzyme systems of the body were revealed.

In spite of this negative attitude towards biochemistry, Leonardo makes two observations on metabolism full of astonishing prescience. In one entitled 'How the body of the animal com tinually dies and is renewed' he enters at length into a discussion of the necessity for an exact balance between nourishment supplied to the bods and that consumed by the tissues. "Unless yog supply nourishment equivalent to that which has departed, life fails in its vigour, and if you deprivg it completely of this nourishment life is destroyed But if you supply it with just so much as destroyed day by day, then it renews its life just as much as it is consumed, like the light of candle whose light is also constantly renewed b swiftest succour from beneath in proportion as the upper part is consumed and dies.' Here is cleå anticipation of a metabolic 'balance' which is. reflected in such modern laboratory procedures a nitrogen and fat balances.

And again, with regard to 'salt'-'The human race has perpetually been, and will ber consumers of salt. And if the whole mass of the earth were composed of salt it would not suffice for human food. Therefore either the substance of the salt is everlasting ... or it dies and is res newed together with the men who consume ie But since experience tells us it does not die (an $\$$ various examples are given) there must negds pass through human bodies as urine, perspiration or other excretions as much salt as is brought every year into the cities.' Here he not only cơne ceives of a salt balance but suggests to us a metho for showing it!

In so brief an account of Leonardo's physiologe there is not opportunity to summarize his work of the physiology of all the systems of the body. $\vec{\Phi}$ have therefore attempted to illustrate how Leonardo approached such problems by consisten application of certain principles-the most important of which was mechanistic in nature. An though it is in general true that his success was in. proportion to the mechanical nature of the problem confronting him an exception occurs in his failure. to shake off Galenic theory with regard to the heart.

Leonardo's awareness of the incompleteness o요 his understanding of human physiology expresse itself poignantly in the cry "Would that it might: please our Creator that I were able to reveal the nature of man and his habits even as I describe his figure.'

\section{BIBLIOGRAPHY}

MCMILLAN, I. K. R., DALEY, R., and MAT'THEWS, M.ष् (I 952), Brit. Heart $\mathcal{F}$., 14, 42. 